\title{
La mutualisation des risques et ses effets sur le fonctionnement des gouvernements des villes côtières portugaises au Moyen Âge
}

Risk mutualisation and its impact on the governance of Portuguese coastal towns in the Middle Ages

\section{Mário Farelo}

\section{(2) OpenEdition}

\section{Journals}

\section{Édition électronique}

URL : http://journals.openedition.org/abpo/2628

DOI : $10.4000 / a b p o .2628$

ISBN : 978-2-7535-2843-7

ISSN : 2108-6443

\section{Éditeur}

Presses universitaires de Rennes

\section{Édition imprimée}

Date de publication : 30 juin 2013

Pagination : 193-211

ISBN : 978-2-7535-2838-3

ISSN : 0399-0826

Référence électronique

Mário Farelo, «La mutualisation des risques et ses effets sur le fonctionnement des gouvernements des villes côtières portugaises au Moyen Âge », Annales de Bretagne et des Pays de l'Ouest [En ligne], 120-2 | 2013, mis en ligne le 30 juin 2015, consulté le 01 mai 2019. URL : http:// journals.openedition.org/abpo/2628; DOI : 10.4000/abpo.2628 


\title{
La mutualisation des risques et ses effets sur le fonctionnement des gouvernements des villes côtières portugaises au Moyen Âge
}

\author{
Mário FARELO \\ Docteur en histoire médiévale, chercheur membre de l'Instituto \\ de Estudos Medievais - Universidade Nova de Lisboa
}

Les Portugais ont, au Moyen Âge, tout à la fois recherché et craint la mer. L'océan fut très tôt un espace de travail, pour les pêcheurs d'abord, mais aussi pour les professionnels du transport, dès lors que le commerce dans et hors du royaume s'intensifia. La pêche s'est imposée comme une activité essentielle. Si l'importance des captures fluviales ne doit pas être sous-estimée $^{1}$, les espèces marines - comme la sardine - formaient une part essentielle du régime alimentaire des populations lusitaniennes, non seulement dans les villages (póvoas marítimas) et les villes du littoral, mais aussi chez les gens de l'intérieur. Le poisson frais était acheminé quotidiennement vers l'hinterland par les routes et les fleuves ${ }^{2}$. L'océan et ses ressources constituaient donc une opportunité et une richesse potentielle pour les communautés littorales, comme d'ailleurs pour la Couronne qui ne cessa de promouvoir mais aussi d'imposer fiscalement les activités liées à la mer. Toutefois, l'océan restait une source de craintes : peur des dangers naturels de la mer (naufrages, pertes de vies et de biens...); peur des agressions par voie maritime (les Musulmans infestent jusque très tard les eaux portugaises, puis la course et la piraterie des autres nations européennes constituent un danger récurrent) ${ }^{3}$; peur enfin de périls imaginaires incarnés dans des créatures

1. L'étude fondamentale sur cette question demeure celle de CRUZ COELHO, Maria Helena da, "A Pesca Fluvial na Economia e Sociedade Medieval Portuguesa », Cadernos Históricos, $\mathrm{n}^{\circ} 6,1992$, p. 81-102.

2. Un exemple parmi beaucoup d'autres, les marchands de Santarém venaient chaque jour chercher des sardines à Lisbonne. Arquivo Nacional da Torre do Tombo, Chancelaria de D. Dinis, liv. $3, \mathrm{f}^{\circ} 125 \mathrm{v}^{\circ}-126 \mathrm{v}^{\circ}$ (1318).

3. Ce n'est pas un hasard si, encore en 1294, le roi Denis I $^{\text {r }}$ décide de construire une muraille à Lisbonne pour protéger en premier lieu la Rue Nouvelle et les équipements ser- 
fantastiques et maléfiques, souvent imaginées à partir d'animaux réels ${ }^{4}$. Face à cette somme d'aléas, les gens de la mer recherchèrent la protection des autorités civiles et spirituelles. Nous laisserons de côté les secondes ${ }^{5}$ pour nous centrer sur les premières dans la présente étude.

La première information relative à une protection collective du trafic maritime lusitanien apparaît dans un document de la fin du XIII ${ }^{\mathrm{e}}$ siècle. Le Portugal connaissait alors une période d'expansion commerciale. Cette croissance, soutenue par la Couronne qui ne ménageait pas ses efforts pour privilégier les agents et les intérêts portugais, nécessitait l'injection de capitaux importants. Mais les marchands portugais devaient faire face sur ce terrain à la concurrence des compagnies italiennes et des autres négociants ibériques qui bénéficiaient eux aussi de privilèges consentis par la royauté. Ce problème ne cessa pas d'occuper les marchands portugais durant les deux derniers siècles du Moyen Âge. Ils devaient défendre leurs prérogatives tout en surveillant l'évolution des privilèges accordés à leurs concurrents étrangers. Il leur fallait aussi aller à la conquête des marchés ibériques et européens. Par voie de conséquence, l'internalisation du commerce portugais favorisa le développement de formes d'entraide et de solidarité entre les marchands ${ }^{6}$.

vant aux activités maritimes. L'activité des corsaires étrangers au Portugal a été étudiée pour le $\mathrm{Xv}^{\mathrm{e}}$ siècle par MorAIS BARROS, Amândio Jorge, "O Porto contra os corsários (a expedição de 1469) ", Revista da Faculdade de Letras. História, $3^{\mathrm{e}}$ serie, vol. 1, 2000, p. 11-27.

4. LOPES, Paulo, O Medo do Mar nos Descobrimentos: representações do fantástico e dos medos marinhos $n^{\circ}$ final da Idade Média, Lisbonne, Tribuna da História, 2009.

5. Sur la religiosité des marins portugais au Moyen Âge, voir MoRAIs BARRos, Amândio Jorge, "Entre a perdição e a salvação : a religiosidade dos mareantes portugueses na Idade Média e na época Moderna ", dans Meloni, Maria Giuseppina et SchenA, Olivetta (dir.), Culti, santuari, pellegrinaggi in Sardegna e nella Penisola Iberica tra medioevo ed età contemporanea, Cagliari, CNR/Istituto di Storia dell'Europa Mediterranea, 2006, p. 371-408; DiAS, José, "A religião dos pescadores portugueses ", Oceanos, n 47-48, 2002, p. 94-112. Les confréries de mariniers étaient aussi très présentes dans la procession du Corpus Christi, comme le soutient MoraIs BARros, Amândio Jorge, "S. Pedro de Miragaia : uma confraria de gentes do mar do Porto $\mathrm{n}^{\circ}$ século XV ", Actas do Congresso Internacional "Bartolomeu Dias e a sua época », vol. IV, Porto, Universidade do Porto - Comissão Nacional para as Comemorações dos Descobrimentos Portugueses, 1989, p. 301-310; "A procissão do Corpo de Deus do Porto nos séculos XV e XVI : a participação de uma confraria ", Revista da Faculdade de Letras. História, $2^{\mathrm{e}}$ série, vol. 10, 1993, p. 117-136. La participation des pêcheurs à la procession du Corps de Dieu à Lisbonne est connue par un document de 1474. Arquivo Nacional da Torre do Tombo, Leitura Nova. Livro $4^{\circ}$ da Estremadura, $\mathrm{f}^{\circ} 10$.

6. Le commerce portugais avec le nord de l'Europe au Moyen Âge a été traité en particulier par OlIVEIRA MARQUEs, António Henrique de, "Notas para a História da Feitoria Portuguesa na Flandres, ${ }^{\circ}$ século XV ", Ensaios de História Medieval Portuguesa, $2^{\mathrm{e}}$ édition, Lisbonne, Vega, 1980, p. 159-193; Hansa e Portugal na Idade Média, Lisbonne, Editorial Presença, 1993; VerLinden, Charles, "Deux aspects de l'expansion commerciale du Portugal : Harfleur au XIV e siècle, Middlebourg au XIV et XV siècles ", Revista Portuguesa de História, n 4, 1949, p. 169-209; " Draps des Pays-Bas et du Nord-Ouest de l'Europe au Portugal au Xv ${ }^{\mathrm{e}}$ siècle ", Anuario de Estudios Medievales, n 3, 1966, p. 235261 ; PAVIOT, Jacques, Portugal et Bourgogne au $\mathrm{XV}^{e}$ siècle : recueil de documents extraits des archives bourguignonnes, Lisbonne-Paris, Fondation Calouste Gulbenkian - Centre 
Ce sujet est d'un abord difficile compte tenu de la rareté des sources lusitaniennes qui se limitent à des documents normatifs : pour l'essentiel une documentation royale peu diserte sur la question et de rares archives de confréries. Ne disposant pas des protocoles notariaux ${ }^{7}$, ni des comptabilités douanières centrales et locales, ni - ou bien très peu - de documents relatifs aux corporations, ni même de contrats de transport qui étaient souvent conclus par oral ${ }^{8}$, c'est une ample panoplie de sources de la pratique

Culturel portugais, 1995; ShILLINGTON, Violet Mary, et ChaPMAn, Annie Beatrice, The commercial relations of England and Portugal, réimpression, New York, Burt Franklin, 1970; Geouge, Jennifer, « Anglo-Portuguese Trade during the Reign of João I of Portugal, 13851433 ", dans Bullon-FERnAndes, María (dir.), England and Iberia in the Middle Ages, $12^{\text {th }}$. $15^{\text {th }}$ century: cultural, literary, and political exchanges, New York, Palgrave Macmillan, 2007, p. 119-134; CHILDS, Wendy, "Anglo-Portuguese Relations in the Fourteenth Century ", dans : GILLESPIE, James (dir.), The Age of Richard II, New York, Palgrave Macmillan, 1997, p. 27-49; "Anglo-Portuguese Trade in the Fifteenth Century ", Transactions of the Royal Historical Society, $6^{\mathrm{e}}$ série, $\mathrm{n}^{\circ} 2,1992$, p. 195-219. Pour la Méditerranée voir notamment THEMUDO BARATA, Filipe, Navegação, comércio e relações políticas : os portugueses $n^{\circ}$ Mediterrâneo ocidental (1385-1466), Lisbonne, Fundação Calouste Gulbenkian, 1998; ADÃo DA FONSECA, Luís, Navegación y corso en el Mediterraneo occidental. Los portugueses a mediados del siglo XV, Pampelune, Ediciones Universidad de Navarra, 1978; « Portugal e o Mediterrâneo $\mathrm{n}^{\circ}$ final da Idade Média : uma visão de conjunto ", dans : ADÃo DA FonSECA, Luís et CADEDDU, Maria-Eugenia (dir.), Portogallo mediterraneo, Cagliari, Consiglio Nazionale delle Ricerche, 2001, p. 13-25; " As relações comerciais entre Portugal e os reinos peninsulares nos séculos XIV e XV ", Actas das II Jornadas luso-espanholas de História Medieval, vol. III, Porto, Centro de História da Universidade de Porto, 1987, p. 541-561; Rau, Virgínia, Portugal e o Mediterrâneo século XV. Alguns aspectos diplomáticos e económicos das relações com a Itália, Lisbonne, Centro de Estudos de Marinha, 1973; BERTI, Marcello, « Le aziende da Colle: une finestra sulle relazioni commerciali tra la Toscana ed il Portugallo a metà del Quattrocento ", Toscana e Portogallo. Miscellane storica del $650^{\circ}$ anniversario dello Studio Generale di Pisa, Pisa, ETS, 1994, p. 57-105; MuÑoz PomER, María Rosa, NAVARro EsPinach, German et IGUAL Luís, David, "El comercio portugués en el Mediterráneo occidental durante la Baja Edad Media ", dans GonZÁLEZ JimÉnEZ, Manuel et MonTES Romero-CAMACHO, Isabel (dir.), La Península Ibérica entre el Mediterráneo y el Atlántico. Siglos XIII-XV, SevillaCadíz, Diputación de Cádiz-Sociedad Española de Estudios Medievales, 2006, p. 73-81; Hinojosa MonTAlVVo, José, « De Valencia a Portugal y Flandres. Relaciones durante la Edad Media ", Anales de la Universidad de Alicante. Historia Medieval, n 1, 1982, p. 149-168. En ce qui concerne les synthèses, le manque de recherche fondamentale impose le recours à GAMA BARRos, Henrique da, História da Administração Pública em Portugal nos séculos XIII $a X V$, édition annotée par Torquato Sousa Soares, vol. IX-X, Lisbonne, Livraria Sá da Costa, 1950-1954; OliveIRA MARQues, António Henrique de, Portugal na crise dos séculos XIV e XV, Lisbonne, Editorial Presença, 1987, p. 150-180.

7. Ceux-ci sont pourtant souvent mentionnés dans la documentation de l'époque. Le plus ancien registre conservé est celui d'Antão Diiz, allant d'août 1473 à août 1474 (CRUZ Coelho, Maria Helena da, « Os tabeliães em Portugal. Perfil profissional e sócio-económico (sécs. XIV-XV) ", Historia. Instituciones. Documentos, n 23,1996, p. 173-211; étude mise à jour dans Estudos de Diplomática Portuguesa, Lisboa, Edições Colibri - Faculdade de Letras a Universidade de Coimbra, 2001, p. 93-137; AGUIAR ANDRADE, Amélia, " A estratégia régia em relação aos portos marítimos n ${ }^{\circ}$ Portugal medieval: o caso da fachada atlântica ", dans : Arízaga Bolumburu, Beatriz et Solorzáno Telechea, José Ángel [dir.], Ciudades y villas portuárias del Atlântico en la Edad Media. Nájera. Encuentros Internacionales del Medievo. Actas, Logroño, Instituto de Estudios Riojanos, 2005, p. 58).

8. Vera-Cruz Pinto, Eduardo, "Os Seguros Marítimos nas Rotas Portuguesas do Ultramar : Uma perspectiva Histórico-Jurídica (Século XV-XvI) ", Revista da Faculdade de 
qui ne peut pas être mise à contribution. Cette pénurie documentaire limite considérablement notre connaissance des risques maritimes pesant sur l'activité commerciale et déforme nécessairement l'image que nous pouvons en avoir. Si nous disposons de rares informations sur l'assurance maritime, les données sont un peu plus nombreuses et précises pour les pratiques de type mutualiste et les solidarités horizontales. Nous en sommes réduits, par conséquent, à centrer davantage l'analyse sur ces dernières.

S'agissant des assurances, les contacts noués avec les marchands étrangers, dans et hors du Portugal, laissent à penser que les négociants lusitaniens étaient au fait des techniques commerciales les plus avancées au sein de la Chrétienté. La démonstration en a déjà été faite à propos du crédit $^{9}$. Les affréteurs avaient aussi l'habitude d'expédier leurs denrées en les répartissant entre plusieurs navires. L'étude de rares testaments de marchands laisse même apparaître l'usage de la parsonnerie ${ }^{10}$. Certains auteurs soutiennent aussi l'idée de l'existence au Portugal du resseguro (réassurance), pratique consistant à partager les risques entre divers assureurs. Assurance et réassurance auraient donc été des pratiques beaucoup plus courantes que la médiocrité des sources ne le laisse entrevoir. Ce mode de compensation des risques maritimes ne se substituait toutefois pas au mutualisme, que l'historiographie considère comme une forme de pré-assurance ${ }^{11}$. S'agissant du cas portugais, ce type de solidarité s'exerçait au sein de deux institutions totalement distinctes, disposant chacune d'une organisation propre, poursuivant des objectifs différents et entretenant des relations singulières avec les pouvoirs établis : les caisses communes des marchands (Bolsa dos mercadores) d'une part, d'autre part, les dispositifs d'assistance mutuelle promus par diverses associations urbaines à but caritatif, connues sous les appellations de confréries et d'hôpitaux de marchands, dont certaines s'étendaient aux pêcheurs et aux marins.

\section{Les caisses communes}

Les caisses communes représentaient une forme de mutualisation très répandue au Portugal à la fin du Moyen Âge. Elles fonctionnaient à partir

\footnotetext{
Direito da Universidade de Lisboa, vol. XXXIX, n 1, 1998, p. 260. Une loi du roi Ferdinand ${ }^{\text {er }}$ sur la preuve des contrats, datée de 1379, ordonne qu'il ne soit pas obligé de consigner par écrit les ventes et les achats de marchandises entre les étrangers et les Portugais lorsque celles-ci sont faites par l'intermédiaire de courtiers. Ordenações do Senhor Rey D. Affonso V, vol. III, Lisbonne, Fundação Calouste Gulbenkian, 1984, p. 179.

9. Themudo Barata, Francisco, "Negócios e crédito : complexidade e flexibilidade das práticas creditícias (século xv) ", Análise Social, vol. xxxi, n 136-137, 1996, p. 683-709.

10. Oliveira MARQues, António Henrique de, Portugal na crise dos séculos XIV e XV, op. cit., p. 174-177. Il arrivait aussi qu'une même personne assure tous les navires provenant d'un même port, comme en témoigne une lettre de pardon d'Alphonse $V$ destinée à Diogo Álvares Pinto. Arquivo Nacional da Torre do Tombo, Chancelaria de D. Afonso V, liv. $21, \mathrm{f}^{\circ} 38 \mathrm{v}^{\circ}-39$.

11. Oliveira MARQues, António Henrique de, Para a história dos seguros em Portugal. Notas e documentos, Lisbonne, Arcádia, 1977, p. 16.
} 
de mises de fonds effectuées par les municipalités ${ }^{12}$ ou des groupements professionnels qui cherchaient par ce moyen à protéger leurs membres ${ }^{13}$. La contribution à ces caisses était devenue obligatoire comme l'indique a contrario la documentation royale relative à des exemptions individuelles ou collectives. À partir de la deuxième moitié du Xve siècle, on pouvait être dispensé de contribuer à ces caisses au même titre que la monarchie exemptait de certaines charges municipales : paiement d'impôts, prêt ou transport d'argent, surveillance des prisonniers, tutelle et curatelle des orphelins, charge d'arbalétrier municipal, service sur les vaisseaux du roi, participation aux milices municipales, obligation de détenir un cheval et des armes, ou de donner le gîte et le couvert, etc. ${ }^{14}$.

Ce type de mutualisation semble avoir été précoce parmi les gens de mer. En 1293, le roi Denis I $^{\text {er }}$ (1279-1325) confirma le règlement municipal (postura) des marchands portugais qui créait une caisse commune ayant pour but de couvrir leurs investissements commerciaux en Normandie, en Angleterre, en Flandres et dans le nord-ouest de la France (Bretagne et La Rochelle). Les paiements, obligatoires, étaient répartis en deux catégories : les propriétaires de navires de plus de cent tonneaux devaient payer 20 sous sterling, tandis que les autres acquittaient seulement la moitié. Les sommes provenant de ces impositions devaient être placées en Flandres, lorsqu'elles atteignaient cent marcs d'argent en métal (ou 23 kilogrammes), tandis que le surplus était conservé au Portugal où les marchands décidaient de la meilleure façon de l'employer ${ }^{15}$.

Malheureusement nous perdons très vite la trace de cette bourse, créée au temps de Denis I ${ }^{\text {er }}$. En témoignant de la vitalité du commerce portugais avec la Chrétienté septentrionale, elle a probablement permis en outre le développement de caisses "plus régionales " centrées autour des communautés marchandes des villes portuaires, dont les plus actives étaient Lisbonne et Porto ${ }^{16}$. Tout en demeurant des institutions visant à couvrir les dépenses de construction de navires et à recouvrer les sommes engagées en cas de saisie des nefs ou de perte suite à un accident survenu en cours de route ${ }^{17}$, elles servirent également à défendre les intérêts de

12. Les bourses constituées par les municipalités sont présentes dans la documentation du règne d'Alphonse $\mathrm{V}$ (Arquivo Nacional da Torre do Tombo, Chancelaria de D. Afonso V, liv. $9, \mathrm{f}^{\circ} 15-15 \mathrm{v}^{\circ}$; liv. $2, \mathrm{f}^{\circ} 28 \mathrm{v}^{\circ}-29 \mathrm{v}^{\circ}$; liv. $34, \mathrm{f}^{\circ} 61$; liv. $\left.12, \mathrm{f}^{\circ} 43\right)$.

13. Tel est le cas des hommes chargés de la surveillance des bois (monteiros). Arquivo Nacional da Torre do Tombo, liv. 34, f 203 (1450).

14. Arquivo Nacional da Torre do Tombo, liv. 10, $\mathrm{f}^{\circ} 55$ (1454).

15. Ceux qui ne respectaient pas ce règlement municipal (postura) encouraient une amende de dix livres. Descobrimentos portugueses. Documentos para a sua história, édité par Silva MARQues, João Martins da, vol. I, Lisbonne, INIC, 1944, p. 21-22, n 29.

16. L'existence d'une caisse créée par la municipalité de Setúbal (OLIVEIRA MARQuES, António Henrique de, Para a história dos seguros em Portugal, op. cit., p. 27; Descobrimentos Portugueses, Suplemento ao vol. I, p. 336) laisse entendre que la méthode a pu s'appliquer à d'autres ports portugais.

17. Descobrimentos Portugueses, vol. I, p. 207-208 et 611-612; GAMA Barros, Henrique da, História da Administração Pública em Portugal nos séculos XIII a XV, op. cit., vol. X, p. 358. 
leurs membres. L'exemple habituellement mis en avant est leur capacité à représenter les intérêts portugais lors des accords commerciaux signés avec l'Angleterre en 1352 et 1353 au nom des " communautés de la marine des cités et villes maritimes du Portugal ${ }^{18}$ ".

Les divers fléaux de la deuxième moitié du XIV siècle n'ont pas manqué d'affecter l'efficacité de ces caisses ${ }^{19}$ tout autant que l'activité commerciale et maritime en général, bien que l'historiographie considère que cette conjoncture de crise a aussi fourni des opportunités commerciales aux marchands ibériques ${ }^{20}$. C'est dans un contexte de relance du commerce maritime national ${ }^{21}$ qu'il faut replacer l'ordonnance de Ferdinand Ir (1367-1383) sur la Compagnie des nefs (Companhia das Naus), connue seulement à travers le résumé qu'en a fait le chroniqueur Fernão Lopes dans sa Crónica de D. Fernando ${ }^{22}$. L'objectif premier de cette ordonnance était de remplacer les navires perdus par l'achat de nouveaux, même si le roi envisageait d'affecter l'argent collecté à " tout ce qui était considéré profitable à tous ".

Il s'agit d'une fondation à portée nationale, puisque les douze navires du roi devaient eux aussi verser, au même titre que les autres participants, les $2 \%$ prélevés sur la valeur de tous les voyages et affrètements " à l'aller et au retour ". Un même souci de portée générale sous-tend la volonté royale de dresser un inventaire exhaustif de tous les navires de plus de cinquante tonneaux. L'objectif était clair : connaître à fond les capacités de la flotte marchande portugaise à l'époque, comme en

18. Oliveira Marques, António Henrique de, Para a história dos seguros em Portugal, op. cit., p. 23; Portugal na crise dos séculos XIV e XV, op. cit., p. 109-110; GAMA BaRROS, Henrique da, História da Administração Pública em Portugal nos séculos XIII a XV, op. cit., vol. X, p. 231235; « Bolsas marítimas », dans SERRÃo, Joel (dir.), Dicionário de História de Portugal, vol. I, Porto, Editora Figueirinha, 1986, p. 355-356.

19. En 1397, Jean $\mathrm{I}^{\mathrm{er}}$ affirme que la création de ces caisses était déjà une des préoccupations de ses prédécesseurs. GAMA BARRos, Henrique da, História da Administração Pública em Portugal nos séculos XIII a XV, op. cit., vol. X, p. 259.

20. Oliveira Marques, António Henrique de, Portugal na crise dos séculos XIV e XV, op. cit., p. 151; Morais Barros, Amândio Jorge, A Confraria de S. Pedro de Miragaia do Porto $n^{\circ}$ Século $X V$, mémoire de maîtrise en histoire médiévale multigr., Faculdade de Letras da Universidade do Porto, 1991, p. 80.

21. Cette ordonnance doit être mise en relation avec les autres mesures prises par Ferdinand $\mathrm{I}^{\mathrm{er}}$ pour développer le commerce maritime (octroi de privilèges et exemption pour ceux qu'achetaient ou fabriquaient des navires de plus de 100 tonneaux, entre autres). Pour le détail de ces mesures, voir LoPEs, Fernão, Crónica de D. Fernando, $2^{\mathrm{e}}$ édition critique, introduction et index de MACCHI, Giuliano, Lisbonne, Imprensa Nacional-Casa da Moeda, 2004, chap. xc, p. 317; Gama Barros, Henrique da, História da Administração Pública em Portugal nos séculos XIII a XV, op. cit., vol. IX, p. 362-263; AZEVEDO, Lúcio de, Elementos para a história económica de Portugal, sécs. XII-XVII, Lisbonne, Gabinete de Investigação do Instituto de Ciências Económicas e Financeiras, 1967, p. 58; VERA-CruZ PINTO, Eduardo, " Os Seguros Marítimos nas Rotas Portuguesas do Ultramar: Uma perspectiva Histórico-Jurídica (Século XV-XVI) ", art. cit., p. 265, note 58; MoraIS BARRos, Amândio Jorge, Porto : a construção de um espaço marítimo nos alvores dos tempos modernos, thèse de doctorat en histoire moderne multigr., Faculdade de Letras da Universidade do Porto, 2004, vol. I, p. 229, note 498.

22. Lopes, Fernão, Crónica de D. Fernando, op. cit., chapitre xCI, p. 319-324. 
témoigne l'exhaustivité de l'enquête qui devait inclure des informations sur le prix d'achat ou de construction des bâtiments, leur valeur et la date de mise à l'eau. Par ailleurs, elle devait consigner tous les revenus générés par l'utilisation de ces mêmes navires. Ce type d'institution ne peut être confondu avec les caisses vues précédemment, même si cette nouvelle bourse était, elle aussi, établie à Lisbonne et à Porto. Il ne s'agit plus de bourses " régionales ", mais bien d'une bourse " nationale " avec deux sièges, sur laquelle nous n'avons par ailleurs que très peu d'informations quant à son fonctionnement.

Il est probable que l'application de cette disposition fut très rapide, dans la mesure où un document de 1380 y fait déjà allusion. Même si le chroniqueur prétend que cette caisse s'imposa dans le royaume, les troubles dynastiques affectèrent très vite son fonctionnement, obligeant la municipalité de Porto à demander au roi sa réactivation, ce qu'il fit par des lettres datées de $1397^{23}$. Il reste à savoir dans quelle mesure cette compagnie s'est substituée aux antérieures caisses municipales, bien que le registre de la bourse des marchands de Lisbonne de $1472^{24}$ suggère une complémentarité plus qu'une véritable substitution.

Par ailleurs, le principe mutualiste progressait dans les villes portuaires fréquentées par les Portugais. À défaut de pouvoir brosser un tableau d'ensemble, il est possible néanmoins de rendre compte de l'existence de ce type de caisse à Harfleur, où les marchands s'en servaient pour maintenir les privilèges acquis dans ce port depuis la première concession par Philippe Le Bel en $1310^{25}$. Son but n'était pas de couvrir le risque maritime mais bien de défendre les intérêts portugais. La plus connue demeure cependant la bourse des marchands portugais à Bruges, où tout marchand qui chargeait dans un vaisseau portugais devait contribuer à la caisse de cette nation. Celle-ci, peut-être une réminiscence de la bourse dionysienne déjà mentionnée, demeura active vers l'époque moderne ${ }^{26}$. Le même principe s'appliquait aux marchands étrangers qui fréquentaient les ports lusitaniens, bien que le seul exemple connu soit la caisse des marchands bourguignons à Lisbonne, mentionnée dans le règlement de la confrérie

23. Gama Barros, Henrique da, História da Administração Pública em Portugal nos séculos XIII $a$ XV, op. cit., vol. X, p. 259.

24. Arquivo Nacional da Torre do Tombo, Leitura Nova. Livro $4^{\circ}$ da Estremadura, $\mathrm{f}^{\circ} 49-50$; Livro $12^{\circ}$ da Estremadura, $\mathrm{f}^{\circ} 30-31$.

25. Arquivo Municipal de Lisboa - Arquivo Histórico, Livro I de Cortes, ${ }^{\circ} 14$ (1395). Sur ces privilèges, voir VERLINDEN, Charles, " Deux aspects de l'expansion commerciale du Portugal : Harfleur au XIV e siècle, Middlebourg aux XIV e et XV ${ }^{\mathrm{e}}$ siècles ", art. cit., p. 169-209. Pour son utilisation par les maîtres et les étudiants séjournant à l'Université de Paris : FARELO, Mário, La peregrinatio academica portugaise vers l'Alma mater parisienne, XII $X V^{e}$ siècles, mémoire de maîtrise en histoire multigraphié, Université de Montréal, 1999; "Les Portugais à l'Université de Paris au Moyen Âge. Aussi une question d'acheminements de ressources ", Memini. Travaux et Documents publiés par la Société des études médiévales du Québec, n5 2001, p. 101-129.

26. Oliveira Marques, António Henrique de, Para a história dos seguros em Portugal, op. cit., p. 27. 
(compromisso) qu'ils établirent en 1472 dans une chapelle de l'église du couvent des Dominicains ${ }^{27}$.

\section{Les associations d'assistance mutuelle}

L'assistance mutuelle associée aux caisses pouvait aussi prendre corps à partir des institutions à but caritatif et confraternel présentes dans les villes sous la forme de confréries, d'hôpitaux et de maisons d'accueil (albergarias) fondés par les gens de mer. Ces institutions confraternelles d'entraide furent très tôt mises sur pied au Portugal, à la suite d'un mouvement entamé par les confréries ecclésiastiques au XII ${ }^{\mathrm{e}}$ siècle ${ }^{28}$. Selon des travaux récents ${ }^{29}$, les institutions de ce type liées aux confréries de mariniers se répartissaient dans deux aires spécifiques : le nord et l'extrême sud du Portugal.

La concentration des confréries et des hôpitaux était forte dans la zone nord dominée par Porto, ville très liée aux activités maritimes et en relation étroite avec la Galice. Elle se produit de bonne heure, puisque la confrérie de Notre-Dame de Sá d'Aveiro est connue dès $1200^{30}$ et celle de Notre-Dame de la Bonne Nouvelle apparaît dès $1247^{31}$. La documentation de la fin du $\mathrm{XIV}^{\mathrm{e}}$ et du début du XV $\mathrm{XV}^{\mathrm{e}}$ siècle fait aussi état d'autres confréries de mariniers dans la région de Porto : la confrérie des âmes du Corps Saint dans le petit village de Massarelos (1394) ${ }^{32}$, la confrérie du Sanctissime Sacrement et des âmes Porto même (1395) ${ }^{33}$, la confrérie du Saint-Esprit de Miragaia

27. Gama Barros, Henrique da, História da Administração Pública em Portugal nos séculos XIII a XV, op. cit., vol. X, p. 210-212.

28. Tavares Pimenta Ferro, Maria José, Pobreza e morte em Portugal na Idade Média, Lisbonne, Editorial Presença, 1989, p. 102.

29. Les données sont tirées de la thèse de ConcEIÇÃo RodRIGUES, Jorge Manuel da, A Confraria das almas do Corpo Santo de Massarelos e as suas congéneres de mareantes, mémoire de maîtrise en histoire moderne multigr., Faculdade de Letras da Universidade do Porto, 2002, p. 29-64. Des détails sur la question peuvent être aussi recueillis dans l'article de Morais BarRos, Amândio Jorge, "Irmandades do mar (marinheiros, mercadores e Inquisição $n^{\circ}$ Porto dos séculos XV e XVI)", dans CALO LouRIDO, Francisco (dir.), Pontevedra e o mar. Simpósio de História Marítima do século XIII ao XVI, Pontevedra, Concelho de Pontevedra, 2003, p. 73-94.

30. FERREIRA NEVES, Francisco, "A Confraria dos Pescadores e Mareantes de Aveiro (12001855) ", Arquivo do Distrito de Aveiro, vol. 39, n 156, 1973, p. 241-271; CONCEIÇÃo RODRIGUES, Jorge Manuel da, A Confraria das almas do Corpo Santo de Massarelos e as suas congéneres de mareantes, op. cit., p. 29-30.

31. Coutinho Lanhoso, Adriano, " Nossa Senhora Protectora dos Mareantes do Velho Burgo do Porto ", Boletim Cultural da Câmara Municipal do Porto, vol. 29, 1966, p. 109112; publié ensuite dans $O$ rio e o mar na vida da cidade. Exposição documental, Porto, Câmara Municipal do Porto - Gabinete de História da Cidade, 1966, p. 200-230 ; ConCEIÇÃo Rodrigues, Jorge Manuel da, A Confraria das almas do Corpo Santo de Massarelos e as suas congéneres de mareantes, op. cit., p. 30.

32. Conceição Rodrigues, Jorge Manuel da, A Confraria das almas do Corpo Santo de Massarelos e as suas congéneres de mareantes, op. cit., p. 34.

33. Ibidem, p. 34. 
$(1405)^{34}$ ou encore de la Fraternité de Notre-Dame de la Pitié, elle aussi à Porto $(1484)^{35}$. Ces institutions se caractérisent, semble-t-il, par un recrutement qui ne semble pas faire de distinction entre les divers professionnels de la mer. En effet, un ensemble varié de professions se retrouve dans celles-ci, allant des charpentiers de navires aux marchands ${ }^{36}$. Cela explique que les marchands de Porto, bien que dotés d'un véritable pouvoir politique $^{37}$, n'ont pas de confrérie spécifique avant le $\mathrm{XvI}^{\mathrm{e}}$ siècle $^{38}$.

L'autre pôle de développement confraternel concernant les gens de mer se localise dans l'Algarve, région marquée par la proximité de la mer et l'importance des activités liées à la pêche. Les confréries et les hôpitaux apparaissent dans la documentation à la fin du XIV ${ }^{\mathrm{e}}$ siècle : les confréries du Corps Saint des mariniers de Tavira $(1382)^{39}$, de Faro $(1392)^{40}$ et de Lagos $(1412)^{41}$, celle du Saint-Esprit de Tavira $(1442)^{42}$ et la fraternité de NotreDame de l'Espoir de Portimão (1497) ${ }^{43}$.

Ces institutions se mettent également en place dans d'autres régions au cours du Xv siècle, à l'instar de celles qui se créent dans la péninsule de Setúbal (la confrérie des mariniers de Sesimbra et la confrérie et l'hôpital du corps Saint à Setúbal) ${ }^{44}$. L'important travail de dépouillement de Jorge Rodrigues sur les confréries et les hôpitaux ne fait pas état de la présence de ces institutions à Lisbonne avant le $\mathrm{XVI}^{\mathrm{e}}$ siècle ${ }^{45}$, ce qui semble être contradictoire au regard de la création précoce des caisses présentées auparavant. En réalité, ce constat reflète avant tout les carences de la

34. Ibid., p. 34; Morais Barros, Amândio Jorge, A Confraria de S. Pedro de Miragaia do Porto $n^{\circ}$ Século $X V$, op. cit., p. 32.

35. Conceição Rodrigues, Jorge Manuel da, A Confraria das almas do Corpo Santo de Massarelos e as suas congéneres de mareantes, op. cit., p. 40.

36. Guimarães SÁ, Isabel, "Confrarias e misericórdias ", dans : Oliveira, César, (dir.), História dos municípios e do Poder Local (dos finais da Idade Média à União Europeia), Lisbonne, Círculo de Leitores, 1996, p. 57-58.

37. Les oligarchies municipales à Porto et la présence des marchands dans cette ville donnèrent lieu à l'élaboration de trois études importants: SouSA, Armindo de, « Conflitos entre o bispo e a Câmara do Porto nos meados do século XV - 1ª parte ", Boletim Cultural da Câmara Municipal do Porto, 2 e serie, vol. 1, 1983, p. 9-103; MiLlán CosTA, Adelaide, "Vereação »e "Vereadores ": o governo do Porto em finais do século XV, Porto, Câmara Municipal-Arquivo Histórico, 1993; BRITo, Pedro de, Patriciado urbano Quinhentista: as famílias dominantes do Porto (1500-1580), Porto, Câmara Municipal-Arquivo Histórico, 1997.

38. Morais Barros, Amândio Jorge, Porto : a construção de um espaço marítimo nos alvores dos tempos modernos, op. cit., p. 110.

39. Conceição Rodrigues, Jorge Manuel da, A Confraria das almas do Corpo Santo de Massarelos e as suas congéneres de mareantes, op. cit., p. 30.

40. Ibidem, p. 33.

41. Ibid., p. 37.

42. Ibid., p. 37.

43. Ibid., p. 41.

44. Ibid., p. 42. L'auteur de ce travail identifie encore pour la période médiévale la confrérie des mariniers de Caminha (1488) et la fraternité du Corps Saint à Funchal (Xve siècle).

45. Ibid., p. 50 sq. 
46. La question des confréries et des hôpitaux dans la Lisbonne médiévale a donné lieu à une abondante bibliographie, laquelle s'appuie surtout sur l'historiographie produite sur la ville de Lisbonne à l'époque moderne et sur la documentation des diverses institutions ecclésiastiques (collégiales et monastères) de la ville, étant donné la disparition de la documentation médiévale (RosA, Maria de Lurdes, "Sociabilidades e espiritualidades na Idade Média : a historiografia portuguesa sobre os comportamentos religiosos dos leigos medievais ", Lusitania sacra, $2^{\mathrm{e}}$ série, 21 [2009], p. 78, note 18). Les études les plus importantes sur les institutions d'assistance à Lisbonne pendant le Moyen Âge sont celles de AnICETo, Maria Emília, et JASMins PereIRA, Fernando, " Assistência na Idade Média ", dans : BANHA DE ANDRADE, António (dir.), Dicionário de História da Igreja em Portugal, vol. I, Lisbonne, Editorial Resistência, 1980, p. 640-661; CARMONA, Mário, O Hospital Real de todos os Santos da cidade de Lisboa, Lisbonne, (s.n.), 1954; CARVALHO, Sérgio Luís de, Instituições assistenciais da idade média portuguesa, Lisbonne, Grupo de Trabalho do Ministério da educação para as Comemorações dos Descobrimentos portugueses, 1995, p. 17-51; CASTILHO, Júlio de, "A extinta irmandade do Espírito Santo do Lumiar. Estudo do seu antigo compromisso ", Archivo Historico Portuguez, n 1, 1903, p. 97-101; CHAVEs, Luís, "Instituições dos homens do mar : confrarias e hospitais deles ", Lisboa nas auras do povo e da história: ensaios de etnografia, vol. 4, Lisbonne, Câmara Municipal de Lisboa, 1969, p. 197-208; SiLvA CoRREIA, Fernando da, "Os velhos hospitais de Lisboa Antiga ", Revista Municipal, ano 2, n 10 (1941), p. 3-13; Origens e formação das misericórdias portuguesas, Lisbonne, Henrique Torres, 1944; Regimento do Hospital de Todos-os-Santos, Lisbonne, Sanitar, 1946; SousA CosTA, António Domingues de, " Hospitais e albergarias na documentação pontifícia da segunda metade do século XV ", A pobreza e a assistência aos pobres na Península Ibérica durante a Idade Média. Actas das $1^{\text {as }}$ Jornadas Luso-Espanholas de Historia Medieval, Lisboa, 25-30 de Dezembro de 1972, vol. I, Lisbonne, Faculdade de Letras da Universidade de Lisboa-Instituto da Alta Cultura, 1973, p. 259-327; DeNIS, Ferdinand Jean, Le Portugal : Lisbonne au Moyen Âge et Lisbonne au temps de la Renaissance. Apogée et splendeur de cette cité, Paris, Firmin Didot, 1846, p. 214-218; Costa, Goodolphim, As Misericórdias, $2^{\mathrm{e}}$ ed., Lisbonne, Livros Horizonte, 1998; LEME, Margarida, O património dos hospitais medievais na Lisboa manuelina, rapport du séminaire História Económica e Social du cours de maîtrise en histoire et archéologie médiévales multigr., Faculdade de Ciências Sociais e Humanas de l'Universidade Nova de Lisboa, 2006; Gomes MARTins, Miguel, "Entre a gestão e as ingerências: a administração hospitalar na Lisboa de Quatrocentos ", João Afonso de Santarém e a assistência hospitalar escalabitana durante o Antigo Regime, Santarém, Câmara Municipal de Santarém, 2000, p. 121-131; MöRSDORF, Klaus, A irmandade de São Bartolomeu dos alemães em Lisboa, Lisboa, (s.n.), 1958; NogueIRA, José Maria António, "Algumas notícias acerca dos hospitais existentes em Lisboa e suas proximidades antes da fundação do hospital de Todos os Santos - 15 de Maio de 1492 ", Esparsos : Arqueologia, etnografia, bibliografia e história, Coimbra, Imprensa da Universidade, 1934, p. 75-125; ROSA PEREIRA, Isaías da, " As obras de misericórdia na Idade Média: as mercearias de Maria Esteves ", A pobreza e a assistência aos pobres na Península Ibérica durante a Idade Média, op. cit., p. 717-759; OLIVEIRA RAMOS, Luís de, " Do Hospital Real de Todos os Santos à história hospitalar portuguesa ", Revista da Faculdade de Letras. História, $2^{\mathrm{e}}$ série, n 10, 1993, p. 333-350; REIS, Maria Fátima, " Resistências e sentidos do culto do Espírito Santo em Lisboa na Época Moderna ", dans : SERRÃo, Vicente (dir.), Em nome do Espírito Santo. História de um Culto, Lisbonne, Instituto dos Arquivos Nacionais/ Torre do Tombo, 2004, p. 61-67; SAMPAYO RiBeIRo, Mário de, "A propósito da inscrição sepulcral do fundador da Ermida de Nossa Senhora da Oliveira ", Olisipo. Boletim do Grupo de Amigos de Lisboa, année 21, n 82, Abril 1958, p. 133-141; RosA, Maria de Lurdes, "A religião $\mathrm{n}^{\circ}$ século: vivências e devoções dos leigos ", dans : MoreIRA AzEvEDo, Carlos (dir.), História Religiosa de Portugal, vol. I: Formação e limites da Cristandade, dans : JoRGE, Ana Maria C. et Rodrigues, Ana Maria S. (dir.), Lisbonne, Círculo dos Leitores, 2001, p. 423-510; MeSTRINHO SAlgado, Anastásia et SAlgado, Abílio José, " Hospitais de Lisboa até ao séc. XV ", Oceanos, $\mathrm{n}^{\circ}$ 4, Julho 1990, p. 103-109; "Hospitais Medievais ", dans : SANTANA, Francisco et SucEnA, 
lacunes, ne serait-ce que partiellement. En effet, les données qui suivent suggèrent l'idée que les hôpitaux des mariniers étaient plus spécialisés à Lisbonne que dans le reste du pays. Les divers métiers associés à l'activité maritime se partageaient entre les corporations, les confréries et les hôpitaux des pêcheurs, des courtiers, des charpentiers et des marchands.

Les pêcheurs lisbonnais disposaient au Moyen Âge de quatre institutions caritatives attestées pour la plupart à la fin du XIII ${ }^{\mathrm{e}}$ ou au début du XIV ${ }^{\mathrm{e}}$ siècle. L'une des plus énigmatiques est l'hôpital situé dans la ville basse $^{47}$ et désigné sous le nom d'hôpital de Sainte-Marie $(1418)^{48}$, d'hôpital des pêcheurs (1433) ${ }^{49}$ ou d'hôpital des pêcheurs de Cataquefarás (1494) ${ }^{50}$. Un document daté de 1418 assurait qu'à cette date il existait depuis au moins cent ans. Il se situait dans la paroisse Saint-Julien, rue de la Moreira ${ }^{51}$. En raison de son déplacement dans la paroisse des Martyres en $1494^{52}$, on le localise tantôt dans la première tantôt dans la seconde paroisse ${ }^{53}$.

Les pêcheurs de Lisbonne pouvaient compter sur trois autres institutions confraternelles dans le quartier de l'Alfama. Établie dans la paroisse de Saint-Étienne, près de la Fontaine des chevaux (Fonte dos Cavalos), et attestée entre les années $1366^{54}$ et $1502^{55}$, l'albergaria des pêcheurs (1366, $1374)^{56}$ était aussi connue sous le nom d'hôpital de Pedro Gonçalves ${ }^{57}$.

Eduardo (dir.), Dicionário da História de Lisboa, Lisbonne, Carlos Quintas \& Advogados, 1994, p. 442-446; Veríssimo SERRÃo, Joaquim, A Misericórdia de Lisboa. Quinhentos Anos de História, Lisbonne, Livros Horizonte, 2000; PIMENTA FerRo TAVAREs, Maria José, " Nótulas para o estudo da assistência hospitalar aos pobres, em Lisboa : os hospitais de D. Maria de Aboim e do conde D. Pedro ", A pobreza e a assistência aos pobres na Península Ibérica durante a Idade Média, op. cit., p. 371-400; Pobreza e morte em Portugal na Idade Média, Lisbonne, Editorial Presença, 1989.

47. Biblioteca Nacional de Portugal, Fundo General, códice $9463, \mathrm{f}^{\circ} 9 \mathrm{v}^{\circ}-12$. Nous remercions le Dr. Pedro Pinto qui a attiré notre attention sur les documents concernant les confréries de pêcheurs de Lisbonne contenus dans ce registre.

48. Biblioteca Nacional de Portugal, Fundo General, códice 9463, f $^{\circ} 9$ vº -12.

49. Arquivo Nacional da Torre do Tombo, Convento do Salvador de Lisboa, liasse 9 , $\mathrm{n}^{\circ} 181$.

50. Arquivo Nacional da Torre do Tombo, Leitura Nova. Livro $6^{\circ}$ da Estremadura, $\mathrm{f}^{\circ} 124 \mathrm{v}^{\circ}-126$.

51. Biblioteca Nacional de Portugal, Fundo General, códice $9463, \mathrm{f}^{\circ} 9 \mathrm{v}^{\circ}-12$.

52. Arquivo Nacional da Torre do Tombo, Leitura Nova. Livro $6^{\circ}$ da Estremadura, $\mathrm{f}^{\circ} 124 \mathrm{v}$-126; LEME, Margarida, O património dos hospitais medievais na Lisboa manuelina, op. cit., p. 24.

53. CORREIA, Fernando, "Os velhos hospitais de Lisboa Antiga ", art. cit., p. 11; MeSTRINHO Salgado, Anastásia et Salgado, Abílio José, "Hospitais Medievais ", art. cit., p. 444.

54. Il fut prétendu en 1563 que cette institution avait alors plus de 200 ans d'âge. Biblioteca Nacional de Portugal, Fundo General, códice $9463, \mathrm{f}^{\circ}$ 52-54.

55. Arquivo Nacional da Torre do Tombo, Mosteiro de S. Vicente de Fora de Lisboa, première incorporation, liasse $14, \mathrm{n}^{\circ} 18$; Mosteiro de Sta. Cruz de Coimbra, liv. 42, $\mathrm{n}^{\circ} 15$; Colegiada de Sto. Estevão de Alfama de Lisboa, liasse 7, ${ }^{\circ} 139$; Biblioteca Nacional de Portugal, Fundo General, códice $9463, \mathrm{f}^{\circ} 9 \mathrm{v}^{\circ}-12$.

56. Arquivo Nacional da Torre do Tombo, Mosteiro de S. Vicente de Fora de Lisboa, première incorporation, liasse 14, ${ }^{\circ} 18$; Mosteiro de Sta. Cruz de Coimbra, liv. 42, n 15.

57. Mestrinho SAlGADO, Anastásia et SAlgADO, Abílio José, « Hospitais Medievais », art. cit., p. 445; LEME, Margarida, O património dos hospitais medievais na Lisboa manuelina, op. cit., p. 24-25. 
À partir de 1390 cet hôpital semble avoir été administré par la fraternité ou la confrérie dédiée au Saint Esprit qui y fut créée par les pêcheurs et les mariniers du haut d'Alfama ${ }^{58}(1457,1536,1563,1564)^{59}$. Cela explique qu'il soit désormais identifié comme l'hôpital du Saint-Esprit $(1402,1418,1459)^{60}$. Il est possible qu'au cours du $\mathrm{XvI}^{\mathrm{e}}$ siècle, cette institution ait été rattachée aux pêcheurs de Cataquefarás, comme en témoigne un document de 1513. La création du nouvel hôpital de Tous les Saints par le roi Emmanuel I ${ }^{\text {er }}$ entraîna son déménagement en 1502 vers l'autre hôpital que les pêcheurs possédaient dans la paroisse de Saint-Michel de l'Alfama ${ }^{61}$.

Ce dernier hôpital, situé près de la Porte de la Croix (Porta da Cruz) (1502), était associé aux pêcheurs chincheiros, qui utilisait un type d'appât spécifique appelé chinche et qui étaient regroupés dans la confrérie de SaintPierre-Telmo ${ }^{62}$. Par la suite, au cours du XVII ${ }^{\mathrm{e}}$ siècle ${ }^{63}$, ces deux confréries furent déplacées vers l'ermitage de Notre-Dame des Remèdes, appelé aussi ermitage du Saint-Esprit, situé près du chafariz dos cavalos et annexé à la collégiale Saint-Étienne ${ }^{64}$. Cette dernière institution est devenue désormais un important foyer de l'assistance et du mouvement confraternel des pêcheurs de Lisbonne.

Le troisième hôpital de l'Alfama associé aux pêcheurs était celui du Corps de Dieu. À l'instar de la dévotion au Saint Esprit ${ }^{65}$, le culte du Corpus Christi

58. REIS, Maria de Fátima, "Resistências e sentidos do culto do Espírito Santo em Lisboa na Época Moderna ", art. cit., p. 62; Mestrinho SALGAdo, Anastásia et SAlgado, Abílio José, "Hospitais Medievais", art. cit., p. 444.

59. PaIVA, João Pedro (dir.), Portugaliae Monumenta Misericordiarum, vol. II : Antes da Fundação das Misericórdias, Lisbonne, Centro de Estudos de História Religiosa - União das Misericórdias Portuguesas, 2003, p. 170; Biblioteca Nacional de Portugal, Fundo General, códice $9463, \mathrm{f}^{\circ} 7 \mathrm{v}^{\circ}-8 \mathrm{v}^{\circ}, 9 \mathrm{v}^{\circ}-12,52-55$.

60. Arquivo Nacional da Torre do Tombo, Colegiada de Sta. Maria da Madalena de Lisboa, liasse $1, \mathrm{n}^{\circ} 15, \mathrm{f}^{\circ} 4$; Biblioteca Nacional de Portugal, Fundo General, códice 9463 , $\mathrm{f}^{\circ} 9 \mathrm{v}^{\circ}-12$; Arquivo Nacional da Torre do Tombo, Colegiada de Sto. Estêvão de Alfama de Lisboa, liasse $7, \mathrm{n}^{\circ} 139$.

61. Arquivo Nacional da Torre do Tombo, Chancelaria de D. Manuel, liv. $6, \mathrm{f}^{\circ} 89 \mathrm{v}^{\circ}$; Leitura Nova. Livro $9^{\circ}$ da Estremadura, $\mathrm{f}^{\circ} 119-119 \mathrm{v}^{\circ}$.

62. REIS, Maria de Fátima, "Resistências e sentidos do culto do Espírito Santo em Lisboa na Época Moderna ", art. cit., p. 63. Un document de 1564 l'appelle confrérie des Chincheiros de Alfama. Biblioteca Nacional de Portugal, Fundo General, códice $9463, \mathrm{f}^{\circ} 9$ vº 12.

63. Maria de Fátima Reis situe ce passage en 1651-1652 (REIS, Maria de Fátima, "Resistências e sentidos do culto do Espírito Santo em Lisboa na Época Moderna ", art. cit., p. 62).

64. Biblioteca Nacional de Portugal, Fundo General, códice $9463, \mathrm{f}^{\circ} 24$ v -25 ; CARVALHO da Costa, António, Corografia portugueza, e descriçam topográfica do famoso reyno de Portugal, $2^{\mathrm{e}}$ ed., Braga, Typographia de Domingos Gonçalves Gouveia, 1869, p. 384 ; Mestrinho Salgado, Anastásia et Salgado, Abílio José, "Hospitais Medievais ", art. cit., p. 443; ReIS, Maria de Fátima, "Resistências e sentidos do culto do Espírito Santo em Lisboa na Época Moderna ", art. cit., p. 62. La réunion en 1502 de l'hôpital du Saint-Esprit avec celui des chincheiros explique que ce dernier soit aussi connu sous le nom d'hôpital de Notre-Dame des Remèdes dès le XVI" siècle (CORREIA, Fernando, "Os velhos hospitais de Lisboa Antiga ", art. cit., p. 11).

65. L'implantation et le développement de ce culte au Portugal pendant le Moyen Âge dans le cadre des institutions d'assistance sont désormais mieux connus grâces à une série d'études : Almeida, Justino Mendes de, Da confraria do Espírito Santo à Santa Casa da Misericórdia e outros estudos, Benavente, Santa Casa da Misericórdia, 1998; BRÁSIO, 
- lequel dans sa traduction portugaise est devenu paradoxalement le culte porté au Corps de Dieu (Corpo de Deus) - est très précoce, puisqu'on trouve déjà des informations sur son existence au temps de Alphonse III (1348-1279) - sans la procession - et avec celle-ci dès le règne de Jean Ir ${ }^{\text {er }}(1385-1433)^{66}$. Il s'élevait dans la paroisse Saint-Étienne, mais il n'y a pas unanimité quant à son emplacement précis. Les sources divergent sur ce point, les unes le situant au lieu appelé Lapa, d'autres faisant allusion à une fontaine, la fonte do Bonabuquer ou encore la Fonte dos Cavalos. Même si la première mention de son existence date de $1347^{67}$, la documentation de l'époque situe sa création vers 1280 et la met en relation avec les dons d'un chevalier de Lisbonne. Cette institution n'était pas tournée vers l'assistance des pêcheurs à ses débuts. Elle ne le devient que lorsque ce groupe, très présent dans cette paroisse, prend le contrôle de la confrérie qu'y était fondée vers l'année 1410.

Le recoupement de ces données montre que les hôpitaux du Saint-Esprit et du Corps de Dieu constituèrent les principales institutions à travers lesquelles les pêcheurs de Lisbonne organisèrent leur protection face aux aléas de leur métier, tout en s'assurant des privilèges et des exemptions ${ }^{68}$.

Le premier de ces deux patronages servit aussi pour l'hôpital que les marchands entretenaient dans la Pedreira, dans l'actuel Chiado connu comme l'hô-

António, "As confrarias medievais do Espírito Santo, paradigmas das misericórdias ", Actas do Colóquio Presença de Portugal $n^{\circ}$ Mundo, Lisbonne, Academia Portuguesa da História, 1982, p. 69-85; SERRÃo, Vicente (dir.), Em nome do Espírito Santo. História de um Culto, Lisbonne, Instituto dos Arquivos Nacionais/Torre do Tombo, 2004; MATA, Luís, Ser, Ter e Poder. O Hospital do Espírito Santo de Santarém nos finais da Idade Média. Coimbra, Edições Magno, 2000.

66. GonçalVes, Iria, As festas de "Corpus Christi" do Porto, na segunda metade do século Xv : a participação do Concelho, Porto, Livraria Cruz, 1985; Branco Marques da Silva, Maria João Violante, "A procissão na cidade: reflexos em torno da festa do Corpo de Deus na Idade Média Portuguesa ", dans : Tavares Pimenta Ferro, Maria José (dir.), A Cidade. Jornadas Inter e pluridisciplinares. Actas, Lisbonne, Universidade Aberta, 1993, p. 195-217; Morals BarRos, Amândio Jorge, " A procissão do Corpo de Deus do Porto nos séculos XV e XVI : a participação de uma confraria ", art. cit., p. 117-136.

67. Arquivo Nacional da Torre do Tombo, Colegiada de S. Lourenço de Lisboa, liasse 3, $\mathrm{n}^{\circ} 47$. Nous possédons des informations jusqu'en 1466 (Arquivo Nacional da Torre do Tombo), Ordem dos Frades Menores. Província de Portugal. Convento de Sta. Clara de Santarém, liasse 13, n ${ }^{\circ} 962$ et 963 (1348); Mosteiro de S. Vicente de Fora de Lisboa, première incorporation, liasse 15, $n^{\circ} 35$ (1373); Mosteiro de Sta. Cruz de Coimbra, deuxième incorporation, liasse 54, ancienne cote : Alm. 16, m. 10, n. 19 (1377); Mosteiro de S. Vicente de Fora de Lisboa, première incorporation, liasse 18, $\mathrm{n}^{\circ} 22$ (1382); Colegiada de Sto. Estêvão de Alfama de Lisboa, liasse 7, n 137 (1454); Biblioteca Nacional de Portugal, Fundo General, códice $9463, \mathrm{f}^{\circ} 61 \mathrm{v}^{\circ}-64,64 \mathrm{v}^{\circ}-67(1410,1418,1460,1466)$. Elle est désignée sous l'appellation d'albergaria du Corps de Dieu en 1436 (Arquivo Nacional da Torre do Tombo, Colegiada de Sto. Estêvão de Alfama de Lisboa, liasse 7, n 133).

68. Le roi Edouard I ${ }^{\text {er }}$ confirma en 1434 la décision des pêcheurs lisbonnais de n'aller pêcher les dimanches et jours fériés que pour offrir le produit de leur pêche aux hôpitaux dont ils étaient confrères. Portugaliae Monumenta Misericordiarum, op. cit., vol. II, p. 153 et 226-227. Cette question a été traitée dans GARCÊs VENTURA, Margarida, «Em torno do cumprimento do preceito dominical pelos pescadores (sécs. XV-XVIII) ", dans BARROCA, Mário Jorge (dir.), In Memoriam Carlos Alberto Ferreira de Almeida, vol. II, Porto, Faculdade de Letras da Universidade de Porto, 1999, p. 435-448. 
pital du Saint-Esprit des Marchands de Lisbonne $(1400,1467)^{69}$. Cette institution, dont nous commençons maintenant à connaître un peu mieux l'histoire, était administrée dès sa fondation par la confrérie des Marchands, qu'un document conservé jadis dans le chartrier de l'institution situe en 1279, à l'initiative d'un certain Adam (Adão) et de sa femme Sancha ${ }^{70}$. En 1445, elle fusionne avec l'autre confrérie des marchands de la ville, celle des marchands de Saint-François qui avait son siège dans le couvent des Franciscains ${ }^{71}$. Ce rapprochement fut sans doute opéré pour fortifier une institution à laquelle la Couronne avait accordé des privilèges ${ }^{72}$ compte tenu du rôle important des marchands dans la vie économique et politique de la ville dès la fin du Moyen $\widehat{A}_{\mathrm{ge}} \mathrm{e}^{73}$.

D'autres associations de métiers liées à la mer étaient, elles aussi, organisées en confréries et en hôpitaux, à l'exemple des courtiers et des charpentiers. Les premiers avaient un hôpital lui aussi dédié à Saint-Pierre Martyr, ce qui semble attester leurs liens professionnels avec les gens de mer, notamment les pêcheurs ${ }^{74}$. Connu entre 1419 et $1502^{75}$, cet hôpital est

69. Arquivo Nacional da Torre do Tombo, Arquivo do Hospital de S. José, liv. 7, $\mathrm{f}^{\circ}$ 323$328 \mathrm{v}^{\circ}$; Leitura Nova. Livro $4^{\circ}$ da Estremadura, $\mathrm{f}^{\circ} 215 \mathrm{v}-216 \mathrm{v}$. Voir à propos de sa localisation : CORREIA, Fernando, "Os velhos hospitais de Lisboa Antiga ", art. cit., p. 12; MeSTRINHO Salgado, Anastásia et SAlgado, Abílio José, " Hospitais Medievais ", art. cit., p. 444.

70. Carvalho da Costa, António, Corografia portugueza, e descriçam topográfica do famoso reyno de Portugal, op. cit., vol. III, p. 445; Brandão FERrEIRA DE SOUZA, Vicente, Recopilação histórico-biographica do venerável Bartholomeu do Quental, Lisbonne, Typographia de José Baptista Morando, 1867, p. 24-26; SERRÃo, Vicente, "Introdução ", dans SERRÃo, Vicente (dir.), Em nome do Espírito Santo. História de um Culto, op. cit., p. 9; ROCHA, Ilídio, "ESPIRITO SANTO DA PEDREIRA (Convento do)", dans SANTANA, Francisco et SucEna, Eduardo (dir.), Dicionário da História de Lisboa, op. cit., p. 351.

71. Carvalho da Costa, António, Corografia portugueza, e descriçam topográfica do famoso reyno de Portugal, op. cit., vol. III, p. 447; ROCHA, Ilídio, " ESPIRITO SANTO DA PEDREIRA (Convento do) ", art. cit., p. 351.

72. Il s'agit notamment de l'exemption de l'obligation d'assurer le gîte et couvert par Jean I ${ }^{\text {er }}$ et l'octroi d'un juge privatif au temps de son petit-fils Alphonse V en 1458 (CARVAlHo da Costa, António, Corografia portugueza, e descriçam topográfica do famoso reyno de Portugal, op. cit., vol. III, p. 448; BRANDÃo FERREIRA DE SOUZA, Vicente, Recopilação histórico-biographica do venerável Bartholomeu do Quental, op. cit., p. 26).

73. FARElo, Mário, A oligarquia camarária de Lisboa (1325-1433), thèse de doctorat en histoire médiévale multigr., Faculdade de Letras da Universidade de Lisboa, 2008.

74. Le dominicain galicien, saint Pierre Gonçalves Telmo - le fameux " Corps Saint " -, est justement le protecteur des marins. CoElHo DiAs, Geraldo Amadeu, «O Mar e os Portos como catalizadores de religiosidade " in O Litoral em perspectiva histórica (séc. XVI-XVIII) : Actas, Porto, Instituto de História Moderna - Centro Leonardo Coimbra, 2002, p. 283; Conceição Rodrigues, Jorge Manuel da, A Confraria das almas do Corpo Santo de Massarelos e as suas congéneres de mareantes, op. cit., p. 24; ORDAX, Salvador Andrés, "Un Patrono para los Navegantes Portugueses : "O Corpo Santo" ", dans RiBOT GARCíA, Luis Antonio et BELENGUER CEBRIÀ, Ernest (dir.), Las sociedades ibéricas y el mar a finales del siglo XVI : congreso internacional, tome v : El Area Atlântica. Portugal y Flandres, Valladolid, Sociedad Estatal para la Conmemoración de los Centenarios de Felipe II y Carlos V, 1998, p. 128; Galmes, Lorenzo, El bienaventurado Fray Pedro González O.P., San Telmo (estúdio histórico), Salamanca, Editorial San Esteban, 1991; Martins, Mário, «S. Pero Gonçalvez, O. P., o "corpo Santo" e Gil Vicente ", Lusitania Sacra, n 8, 1967-1969, p. 39-55.

75. Arquivo Nacional da Torre do Tombo, Mosteiro de S. Vicente de Fora de Lisboa, deuxième incorporation, boîte $13, \mathrm{n}^{\circ} 79, \mathrm{f}^{\circ} 6 \mathrm{v}^{\circ}$; Leitura Nova, Livro $9^{\circ}$ da Estremadura, 
certainement administré par la confrérie du même nom. Celle-ci ne semble pas relever de la municipalité, même si ses membres lui sont soumis en principe $^{76}$. Le passage sous juridiction municipale ne fut effectif qu'avec son incorporation, à l'instar de nombreux autres hôpitaux de la ville, dans l'hôpital de Tous les Saints qui profita dès lors de ces installations situées dans la paroisse de Sainte-Juste, rue de Saint-Pierre Martyr, dans un quartier marqué par une forte présence musulmane ${ }^{77}$. Quant aux charpentiers dits da Ribeira, qui travaillaient dans le secteur de la construction et de la réparation navale à Lisbonne, ils possédaient l'hôpital de Saint-Vincent du Corbeau dans la paroisse de Saint-Sauveur ${ }^{78}$.

Par ailleurs, les mariniers et les personnes associées aux activités maritimes bénéficiaient d'un réseau d'assistance organisé dans le quartier de l'Alfama autour d'un hôpital placé sous la protection du saint galicien Pierre Gonçalves Telmo. Nous ne disposons d'aucune information sur son fonctionnement pour la période étudiée, sauf qu'il était au nombre des hôpitaux lisbonnais qui furent rattachés à l'hôpital de Tous les Saints à la fin du Xve siècle ${ }^{79}$.

$\mathrm{f}^{\circ} 60-61 \mathrm{v}^{\circ}$; Leitura Nova, Livro $5^{\circ}$ da Estremadura, $\mathrm{f}^{\circ} 46-48$; LEME, Margarida, O património dos hospitais medievais na Lisboa manuelina, op. cit., p. 6 et 18. Le document de 1419 permet de reculer sa date de fondation d'au moins une cinquantaine d'années, dans la mesure où l'historiographie situait traditionnellement sa fondation en 1470 (CORREIA, Fernando, "Os velhos hospitais de Lisboa Antiga ", art. cit., p. 10).

76. Les courtiers sont placés sous la juridiction municipale à Lisbonne, où le conseil de la ville règle leur activité en vertu de leur appartenance au corps des officiers du concelho. CAETANo, Marcello, «Prefácio ", dans LAnghans, Franz-Paul, $A$ antiga organização dos mesteres da Cidade de Lisboa, Lisbonne, Imprensa Municipal, 1968, p. LXV; CAMPOS RoDRIGUES, Maria Teresa, Aspectos da administração municipal de Lisboa $n^{\circ}$ século XV, Lisbonne, Imprensa Nacional, p. 104-105 et 109-110.

77. Arquivo Nacional da Torre do Tombo, Leitura Nova. Livro $5^{\circ}$ da Estremadura, $f^{\circ}$ 46-48; CORREIA, Fernando, "Os velhos hospitais de Lisboa Antiga ", art. cit., p. 10; Mestrinho Salgado, Anastásia et Salgado, Abílio José, " Hospitais Medievais », art. cit., p. 446. Sur la mouraria de Lisbonne, voir AzEvEDo, Pedro de, " Do Areeiro à Mouraria. Topographia histórica de Lisboa ", Archeologo Português, vol. 5, 1899-1900, p. 212-224 et 257-278; OliveIra MARQues, António Henrique de, "A persistência do elemento muçulmano na História de Portugal após a Reconquista. O exemplo da cidade de Lisboa ", Novos Ensaios de História Medieval Portuguesa, Lisbonne, Vega, 1988, p. 96-107; OLIVEIRA, Luís Filipe et VIANA, Mário, "A mouraria de Lisboa ", Arqueologia medieval, n 3, 1993 , p. 191-209 et BARros, Maria Filomena, A comuna muçulmana de Lisboa (sécs. XIV e XV), Lisbonne, Hughin, 1998.

78. Arquivo Nacional da Torre do Tombo, Leitura Nova. Livro $9^{\circ}$ da Estremadura, $\mathrm{f}^{\circ} 13-15 \mathrm{v}^{\circ}$ (1498); $\mathrm{f}^{\circ} 91-93 \mathrm{v}^{\circ}$ (1499); Leitura Nova. Livro $1^{\circ}$ da Estremadura, $\mathrm{f}^{\circ}$ 266-267 (1499); CORREIA, Fernando, "Os velhos hospitais de Lisboa Antiga ", art. cit., p. 10; Mestrinho Salgado, Anastásia et Salgado, Abílio José, " Hospitais Medievais ", art. cit., p. 445; Sousa Gomes, Armando, Carpinteiros da Ribeira das Naus, Coimbra, Imprensa da Universidade, 1931; LEME, Margarida, O património dos hospitais medievais na Lisboa manuelina, op. cit., p. 6 et 16-17.

79. L'intégration concerne les hôpitaux de Saint-Pierre des Pêcheurs à Saint-Michel et du Corps-Saint à Cata-que-Farás, ainsi que ceux des charpentiers et des courtiers. 
Il n'en demeure pas moins que ces confréries et les hôpitaux qui leur étaient associés ${ }^{80}$ - en procédant par analogie - ont dû avoir pour vocation principale la protection spirituelle de leurs membres et l'aide aux orphelins et aux veuves de ceux-ci en cas de difficultés, notamment économiques ${ }^{81}$. Leur configuration comme association confraternelle de métier faisait que la solidarité horizontale se doublait d'une assistance professionnelle. S'il est vrai que les rares règlements intérieurs médiévaux conservés passent sous silence les références expresses à cette mutualisation entre les marins dans l'exercice de leur activité, les rares données disponibles montrent tout de même cette dimension, lorsqu'il est question de l'aide apportée aux confrères qui ne pouvaient plus aller à la mer, du secours porté à des navires en danger ou même lors des opérations liées à l'activité maritime ${ }^{82}$. C'est une forme de mutualisation des risques, liée aux hasards de la vie. Ces divers degrés de protection vont dans le sens d'une consolidation de la cohésion qui pouvait même s'étendre à la protection des incertitudes de la propre activité commerciale, comme en témoigne le cas déjà cité de la confrérie des Bourguignons à Lisbonne.

\section{Les pratiques mutualistes et les gouvernements urbains}

D'après ce que nous venons de voir, il apparaît que les pratiques mutualistes en relation avec les activités maritimes se présentaient comme un phénomène avant tout urbain et étaient liées à des individus remarquables ou à des groupes de pouvoir au sein de la ville. Cette réalité justifie que nous nous intéressions aux relations existant entre ces pratiques et les gouvernements des villes côtières portugaises.

Il n'est pas exagéré de penser que les types de pratiques mutualistes décrits ci-dessus se justifient avant tout par le fait que les municipalités qui dirigeaient les villes portuaires opéraient habituellement sur un mode collectif et que, de surcroît, elles portaient une grande attention aux affaires commerciales. Les magistrats urbains étaient habitués à agir dans un cadre collégial pour résoudre les problèmes, coopter leurs membres, décider des divers aspects de la vie de la communauté au sein de conseils plus ou moins ouverts selon les époques. Rien donc de plus normal que de gérer aussi de façon solidaire les affaires liées à la mer, d'autant plus qu'il existait une relation étroite entre les autorités municipales et le monde des activités maritimes. Les premières ont encadré et réglementé les activités, tel le fret, mais aussi les acteurs (marchands et

80. Morais Barros, Amândio Jorge, "Vida de marinheiro. Aspectos do quotidiano das gentes de mar nos séculos XV e XVI ", dans RibeIRo DA SILVA, Francisco, CruZ, Maria Antonieta, Martins Ribeiro, Jorge et Osswald, Helena (dir.), Estudos em homenagem a Luís António de Oliveira Ramos, vol. I, Porto, Faculdade de Letras da Universidade de Porto, 2004, p. 255.

81. Ibidem, p. 20-21.

82. Ibid., p. 20-21 et 28. 
affréteurs entre autres) tout en défendant leurs privilèges dans le cas de Lisbonne et de Porto ${ }^{83}$.

Par ailleurs, les instances de décision sont dominées par un patriciat très lié à l'activité marchande internationale, notamment dans les deux principales villes portuaires que sont Lisbonne et de Porto. Ce patriciat, luimême en relation avec les gens de mer, peut agir plus facilement pour obtenir des décisions municipales ou des interventions royales en sa faveur. Il n'est donc pas surprenant de voir cette oligarchie mercantile organiser par un règlement municipal (postura) la caisse des marchands que le roi Denis confirma à la fin du XIII siècle. De la même façon, les conseils municipaux sont les promoteurs actifs du développement des caisses urbaines qui sont à l'œuvre au siècle suivant.

Cette compétence municipale s'est trouvée renforcée par la mise en place entre 1367 et 1380 de la Compagnie des nefs (Companhia das Naus). Bien qu'ayant en principe une portée nationale, cette fondation du roi Ferdinand Irr profita en premier lieu à Lisbonne. Outre le fait qu'une des caisses avait son siège dans cette ville, les deux juges (executores) de la compagnie - chargés de trancher les éventuels conflits survenus entre marchands ou entre ces derniers et les autorités publiques - furent des hommes dévoués au roi, mais aussi des oligarques qui firent des carrières remarquables dans le conseil municipal ${ }^{84}$. La volonté de réactiver cette caisse à Porto à la fin du XIV e siècle - que l'on perçoit dans les actes produits alors par le conseil de cette ville - montre bien la place déterminante de l'organisation municipale dans ce processus.

La mainmise importante des municipalités sur ces affaires résulte en partie de la faiblesse du mouvement confraternel sur le plan politique au Portugal pendant tout le Moyen Âge ${ }^{85}$. Les causes sont connues et révèlent de l'inefficacité des confréries à jouer un rôle politique au sein des pouvoirs urbains $^{86}$, de même que de l'entrée tardive des corporations profession-

83. La figure du courtier a été étudiée dans MoraIs BARRos, Amândio Jorge, Porto : $a$ construção de um espaço marítimo nos alvores dos tempos modernos, op. cit., p. 99-100.

84. Voir les parcours de deux de ces juges, Lopo Martins et Gonçalo Peres Canelas, dans FARELO, Mário, A oligarquia camarária de Lisboa (1325-1433), op. cit., p. 454 et 541-547. Par ailleurs, outre leurs responsabilités judiciaires, ils étaient responsables également de l'arche à trois serrures dans laquelle se déposaient les espèces monétaires collectées. Pour l'ensemble de leur travail ils percevaient la somme annuelle de cinquante livres. Oliveira Marques, António Henrique de, Para a história dos seguros em Portugal, op. cit., p. 24-25.

85. Ce point de vue historiographique vaut tant pour le Portugal que pour la castille. Voir : CRuz CoElHo, Maria Helena da, "As confrarias medievais portuguesas : espaços de solidariedades na vida e na morte ", XIX Semana de Estudios Medievales. Estella, 20 a 24 de Julio de 1992, Cofradías, grémios, solidariedades en la Europa Medieval, Pamplona, Gobierno de Navarra - Departamento de Educación y Cultura, 1993, p. 157; MonSALVo ANTón, José Manuel, " Aproximación al estudio del poder gremial en la Edad Media castellana : un escenario de debilidad ", En la España medieval, n 25, 2002, p. 144.

86. Si les élites impliquées dans le négoce international font partie des confréries urbaines (Morais Barros, Amândio Jorge, A Confraria de S. Pedro de Miragaia do Porto 
nelles dans les conseils municipaux ${ }^{87}$. Pour ce qui est des pratiques mutualistes, les rares règlements (compromissos) de confréries de gens de mer connus restent muets, certains datant pourtant du $\mathrm{XIII}^{\mathrm{e}}$ siècle. Faut-il voir ici seulement le fait que ces pratiques n'étaient pas nécessairement mises par écrit, étant donné qu'elles découlaient des devoirs d'aide et assistance dus par tout confrère envers un autre ? Quoi qu'il en soit, il est probable que nous sommes ici confrontés à un problème de mentalité ou, du moins, à une question d'incapacité organisationnelle. En fait, l'historien ne peut que constater une faible réception au Portugal des solutions mutualistes mise en œuvre ailleurs, au même titre que le développement limité des associations commerciales sous la forme de sociétés ou de compagnies ${ }^{88}$. On ne repère pas non plus l'existence de solidarités autour des fédérations régionales telles que les hermandades castillanes ${ }^{89}$.

Século $X V$, op. cit., p. 82), ces associations ne pèsent pas sur le recrutement du conseil municipal comme c'est le cas en Castille (Monsalvo AnTón, José Manuel, "Solidaridades de oficio y estruturas de poder en las ciudades castellanas de la Meseta durante los siglos XIII al XV (aproximación al estudio del papel político del corporativismo artesanal) ", dans VACA LoREnzo, Ángel (dir.), El Trabajo en la Historia. Séptimas Jornadas de Estudios Historicos, Salamanca, Departamiento de Historia Medieval, Moderna y Contemporánea de la Universidad de Salamanca, 1996, p. 39-40). La fondation d'une confrérie a pu parfois se décider en conseil, comme à Loulé, dans l'Algarve, à la fin du Xve siècle (DuARTE, Luís Miguel, "Quando uma igreja morre : histórias do Cristianismo em Loulé ${ }^{\circ}$ final do século XV ", dans Marinho Alves, Natália, CunHA, Maria Cristina et RiBeiro, Fernanda (dir.), Estudos em homenagem ao Professor Doutor José Marques, vol. III, Porto, Département de Sciences et Techniques du Patrimoine et Département d'Histoire, Faculté des Letres de l'Université de Porto, 2006, p. 88-89).

87. La vocation première de ces institutions pour l'assistance spirituelle débouchait aussi sur la légitimation du pouvoir par le culte funéraire qui s'y trouvait dispensé. BRAND, Hanno, "Mémoire individualisée et conscience communautaire - souvenir, charité et représentation au sein des élites de Leyde à la fin du Moyen Âge ", dans BRAND, Hanno, Monnet, Pierre et Staub, Martial (dir.), Memoria, communitas, civitas. Mémoire et conscience urbaines en Occident à fin du Moyen Âge, Ostfildern, Jan Thorbecke Vergal, 2003, p. 88-89.

88. Oliveira Marques, António Henrique de, Portugal na crise dos séculos XIV e XV, op. cit., p. 173; GonZÁlEZ, María Asenjo, "Ciudades y hermandades en la Corona de Castilla. Aproximación socio política ", Anuario de Estudios Medievales, n² 27, 1997, p. 104; CLÁUDIO, Ana Sofia, São as confrarias refúgio dos humildes? Contributo para o Estudo das Elites Eborenses $n^{\circ}$ Final da Idade Média, mémoire de maîtrise en Études historiques européennes multigr., Universidade d'Évora, 2002, p. 116.

89. La seule exception notable est celle de l'hermandad de Rica-Coa, qui s'explique par les racines léonaises des conseils municipaux de cette région incorporée dans le royaume de Portugal seulement après 1297 (BARRIOS GARCíA, Ángel, " El Proceso de Ocupación y de Ordenación del Espacio en la Raya Leonesa ", O Tratado de Alcanices e a importância histórica das terras de Riba Côa : actas do Congresso Histórico Luso-Espanhol, 12-17 Setembro, 1997, Lisbonne, Universidade Católica, p. 155-183; Cruz CoElHo, Maria Helena da, "Riba Côa em Cortes [séc. xv] ", O Tratado de Alcanices e a importância histórica das terras de Riba Côa, op. cit., p. 233-246; BAQuero Moreno, Humberto, " A irmandade de Ribacoa nos fins do Século XIII ", Os municípios portugueses nos séculos XIII a XVI, Lisbonne, Editorial Presença, 1986, p. 27-32; "A irmandade de Ribacoa : novos documentos ", dans BARROCA, Mário Jorge, [dir.], In Memoriam Carlos Alberto Ferreira de Almeida, op. cit., vol. II, p. 121-128; "A zona de Ribacoa à luz do Tratado de Alcañices ", El Tratado de Alcañices. Ponencias y comunicaciones de las Jornadas conmemorativas del VII centenario del Tratado de Alcañices [1297-1997], Zamora, Fundación Rei Afonso Henriques, 1999, p. 173-184; 
Il apparaît donc au terme de cet exposé que la protection des professionnels de la mer au Portugal au Moyen Âge reposait davantage sur les ressources provenant de leur travail et les institutions d'assistance qu'ils ont été capables de créer et d'entretenir. En effet, il faut attendre l'Époque moderne pour que la mutualisation progresse avec le développement des assurances maritimes et l'accroissement de l'intervention de la Couronne, dans le cadre d'une conjoncture tout à fait différente, avec l'établissement d'un courtier spécifique en 1529 et la constitution d'une Chambre des Assurances attestée pour la première fois en $1572^{90}$.

\section{RÉSUMÉ}

Selon les sources historiques disponibles, la protection des risques assumés par les marins portugais au Moyen Âge a pris moins la forme de l'assurance que de la pré-assurance. Cette dernière s'est organisée notamment autour de deux institutions, à savoir les caisses communes des marchands (bolsas dos mercadores) et les diverses associations urbaines à but caritatif connues sous les désignations de confréries et d'hôpitaux de marchands et de pêcheurs. Distinctes dans leurs organisations, leurs objectifs et leurs relations, l'une et l'autre ont constitué des rouages dans la visibilité des oligarchies urbaines et de leurs relations avec les autres pouvoirs établis dans la ville.

\section{ABSTRACT}

According to available historical sources, risk protection for Portuguese sailors in the Middle Ages took less the form of the insurance than that of the pre-insurance. The latter was organised mostly around two institutions, namely the pooled resources of merchants (bolsas dos Mercadores) and various urban charitable associations known under the names of fraternities and hospitals for merchants and seamen. Though separately organised, through their goals and their relations both were involved in highlighting the role of urban oligarchies and their dealings with other powers established in the city.

Duarte NogueiRa, José Artur, "Os municípios medievais em Riba-Côa ", O Tratado de Alcanices e a importância histórica das terras de Riba Côa, op. cit., p. 197-209). Sur les conflits internes aux conseils municipaux au temps du roi Denis ${ }^{\text {er }}$, voir Melo, Arnaldo, "Relações interconcelhias ${ }^{\circ}$ reinado de D. Dinis ", Revista da Faculdade de Letras História, $2^{\mathrm{e}}$ serie, vol. XV, $\mathrm{n}^{\circ} 1$ 1, 1998, p. 545-575.

90. Oliveira MARQues, António Henrique de, Para a história dos seguros em Portugal, op. cit., p. 35 et 37; Borges De Sousa, Vicente, O Controlo e Fiscalização dos Seguros em Portugal. Séculos XIV a XVIII, Lisbonne, Instituto de Seguros de Portugal, 1989; VERA-CRUZ PINTO, Eduardo, "As navegações e os seus riscos : as viagens portuguesas e a origem do seguro marítimo ", dans LuZ Afonso, Simonetta, D'InTino, Raffaella et SoRomENHo, Miguel (dir.), Nossa Senhora dos Mártires. A última Viagem. Catálogo do Pavilhão de Portugal na Expo 98, Lisbonne, Editorial Verbo, 1998, p. 143-153. 